\title{
Interinstitutional Variation of Caesarean Delivery Rates According to Indications in Selected Obstetric Populations: A Prospective Multicenter Study
}

\author{
Gianpaolo Maso, ${ }^{1,2}$ Monica Piccoli, ${ }^{1,2}$ Marcella Montico, ${ }^{1,3}$ Lorenzo Monasta, ${ }^{1,3}$ \\ Luca Ronfani, ${ }^{1,3}$ Sara Parolin, ${ }^{1,2}$ Carmine Gigli, ${ }^{1,4}$ Daniele Domini, ${ }^{1,4}$ Claudio Fiscella, ${ }^{1,5}$ \\ Sara Casarsa, ${ }^{1,5}$ Carlo Zompicchiatti, ${ }^{1,6}$ Michela De Agostini, ${ }^{1,6}$ Attilio D'Atri, ${ }^{1,7}$ \\ Raffaela Mugittu, ${ }^{1,7}$ Santo La Valle, ${ }^{1,8}$ Cristina Di Leonardo, ${ }^{1,8}$ Valter Adamo, ${ }^{1,9}$ \\ Mara Fracas, ${ }^{1,9}$ Giovanni Del Frate, ${ }^{1,10}$ Monica Olivuzzi, ${ }^{1,10}$ Silvio Giove, ${ }^{1,11}$ \\ Maria Parente, ${ }^{1,11}$ Daniele Bassini, ${ }^{1,12}$ Simona Melazzini, ${ }^{1,12}$ Secondo Guaschino, ${ }^{1,2}$ \\ Caterina Businelli, ${ }^{1,2}$ Franco G. Toffoletti, ${ }^{1,2}$ Diego Marchesoni, ${ }^{1,13}$ Alberto Rossi, ${ }^{1,13}$ \\ Sergio Demarini, ${ }^{1,14}$ Laura Travan, ${ }^{1,14}$ Giorgio Simon, ${ }^{1,15}$ Sandro Zicari, ${ }^{1,16}$ \\ Giorgio Tamburlini, ${ }^{1,17}$ and Salvatore Alberico ${ }^{1,2}$
}

${ }^{1}$ Multicenter Study Group on Mode of Delivery in Friuli Venezia Giulia, Institute for Maternal and Child Health (IRCSS) Burlo Garofolo, 34137 Trieste, Italy

${ }^{2}$ Department of Obstetrics and Gynecology, Institute for Maternal and Child Health (IRCCS) Burlo Garofolo, 34137 Trieste, Italy

${ }^{3}$ Epidemiology and Biostatistics Unit, Institute for Maternal and Child Health (IRCCS) Burlo Garofolo, 34137 Trieste, Italy

${ }^{4}$ Department of Obstetrics and Gynecology, Hospital of Gorizia, 34170 Gorizia, Italy

${ }^{5}$ Department of Obstetrics and Gynecology, Hospital of Latisana, 33053 Latisana, Italy

${ }^{6}$ Department of Obstetrics and Gynecology, Hospital of Palmanova, 33100 Palmanova, Italy

${ }^{7}$ Department of Obstetrics and Gynecology, Hospital of Monfalcone, 34070 Monfalcone, Italy

${ }^{8}$ Department of Obstetrics and Gynecology, S. Giorgio Hospital, 33170 Pordenone, Italy

${ }^{9}$ Department of Obstetrics and Gynecology, S. Maria degli Angeli Hospital, 33170 Pordenone, Italy

${ }^{10}$ Department of Obstetrics and Gynecology, Hospital of S. Daniele del Friuli, 33038 S. Daniele del Friuli, Italy

${ }^{11}$ Department of Obstetrics and Gynecology, S. Maria dei Battuti Hospital, 33078 S. Vito al Tagliamento, Italy

${ }^{12}$ Department of Obstetrics and Gynecology, S. Antonio Abate Hospital, 33028 Tolmezzo, Italy

${ }^{13}$ Department of Obstetrics and Gynecology, S. Maria della Misericordia Hospital, University of Udine, 33100 Udine, Italy

${ }^{14}$ Department of Neonatology and Neonatal Intensive Care, Institute for Maternal and Child Health (IRCCS) Burlo Garofolo, 34137 Trieste, Italy

${ }^{15}$ Regional Health Agency of Friuli Venezia Giulia, 33100 Udine, Italy

${ }^{16}$ Department of Statistics and Programming, University La Sapienza, 00185 Rome, Italy

${ }^{17}$ Research Direction, Institute for Maternal and Child Health (IRCCS) Burlo Garofolo, 34137 Trieste, Italy

Correspondence should be addressed to Gianpaolo Maso; gianpaolo.maso@burlo.trieste.it

Received 24 April 2013; Revised 3 June 2013; Accepted 3 June 2013

Academic Editor: Kaei Nasu

Copyright (C) 2013 Gianpaolo Maso et al. This is an open access article distributed under the Creative Commons Attribution License, which permits unrestricted use, distribution, and reproduction in any medium, provided the original work is properly cited. 


\begin{abstract}
The aim of the study was to identify which groups of women contribute to interinstitutional variation of caesarean delivery (CD) rates and which are the reasons for this variation. In this regard, 15,726 deliveries from 11 regional centers were evaluated using the 10 -group classification system. Standardized indications for CD in each group were used. Spearman's correlation coefficient was used to calculate (1) relationship between institutional CD rates and relative sizes/CD rates in each of the ten groups/centers; (2) correlation between institutional CD rates and indications for CD in each of the ten groups/centers. Overall CD rates correlated with both $\mathrm{CD}$ rates in spontaneous and induced labouring nulliparous women with a single cephalic pregnancy at term $(P=0.005)$. Variation of CD rates was also dependent on relative size and CD rates in multiparous women with previous CD, single cephalic pregnancy at term $(P<0.001)$. As for the indications, "cardiotocographic anomalies" and "failure to progress" in the group of nulliparous women in spontaneous labour and "one previous CD" in multiparous women previous CD correlated significantly with institutional $\mathrm{CD}$ rates $(P=0.021, P=0.005$, and $P<0.001$, resp.). These results supported the conclusion that only selected indications in specific obstetric groups accounted for interinstitutional variation of $\mathrm{CD}$ rates.
\end{abstract}

\section{Introduction}

Caesarean delivery $(\mathrm{CD})$ rate is increasing worldwide [1]. In many developed countries, attention is focused on strategies to reduce this trend, given the concern that higher caesarean section rates increase maternal risks, without reducing perinatal mortality [2].

At present, the CD rate in Italy is one of the highest in the world and represents a challenge for the National Public Health system. In 1980, the rate was $11 \%$ and since then it has increased, reaching 39\% in 2008, with significant interregional variations, ranging from $24 \%$ to $62 \%[1,3]$. In order to implement effective measures to reduce this trend and to evaluate temporal or interinstitutional variations of CD rates, several classifications were considered.

A recent systematic review evaluated the advantages and deficiencies of these methodologies [4]. Given the assumption that the aim of an "ideal" classification is to identify the groups of women who contribute significantly to the overall $\mathrm{CD}$ rate and to identify the main factors leading to $\mathrm{CD}$ in specific populations, the authors concluded that the 10-group classification (TGCS) [5], a women-based method, represents, at present, the best system for categorizing the mode of delivery, fulfilling the criteria of standardized, reliable, consistent, and action-oriented classification. Moreover, it has been stressed that this method facilitates auditing, analysing, and comparing $\mathrm{CD}$ rates across different settings and helps creating and implementing effective strategies to optimize CD rates $[6,7]$.

From its introduction in $2001[5,6]$, many studies focused on $\mathrm{CD}$ rates using this classification, but information on indications for performing $\mathrm{CD}$ on each woman according to inter-institutional differences in specific obstetric populations has not been available [8-17].

The aim of our study, carried out on more than 15 thousand deliveries from all of the 11 obstetric departments of our region, was to assess whether inter-institutional variation of overall $\mathrm{CD}$ rates correlated with the size or $\mathrm{CD}$ rates in selected obstetric populations of each institution, defined by using the TGCS. Moreover, we hypothesized that specific indications for $\mathrm{CD}$ in defined obstetric groups might account for overall variation of institutional CD rates.

\section{Material and Methods}

An 18-month prospective study collected data on mode of delivery from all births of the 11 single-institutional obstetric cohorts of Friuli Venezia Giulia (range 369-1,810 deliveries/year/unit). Friuli Venezia Giulia is a region of northeastern Italy accounting roughly for 10,000 deliveries per year with one of the lowest overall regional CD rates in Italy $(23.4 \%$ in 2010). The source institutions, referred as institutions A to M, are first-level departments serving low-risk pregnancies, except for centers I and $\mathrm{M}$ working for a mixed population with the availability of a neonatal intensive care unit (NICU, second referral units).

The units differed for number of deliveries/year as follows: units A, B, C, E, F, G, H, and L had less than 1,000 deliveries/year; center $\mathrm{D}$ accounted for 1,000-1,500 deliveries/year; 1,500-2,000 deliveries/year were assisted in institutions I and $\mathrm{M}$.

To avoid potential information bias due to different definitions on collected data, we created a regional standardized computerized database with the collaboration of all centers. All centers approved and validated the data collection form. All obstetricians and midwives of all the centers were instructed to manage the database and to collect data. Information on institutional deliveries was prospectively collected at the time of delivery by obstetrician or midwife attending the delivery in each center. Collected data were systematically reviewed every month by the referent obstetrician of each center. Special attention was devoted to overall data completeness and accuracy. During the study period, two of the authors (GM and SA) organized periodical multicenter meetings to discuss the results and provide assistance. All women provided informed consent to include their records in the presentation of summary data for births.

The study was approved by the institutional review board of the coordinating center (Technical Scientific Committee (CTS), Institute for Maternal and Child Health (IRCCS Burlo Garofolo, Trieste, project 86/05) February 28, 2007) and access to the data was approved by all hospital trust administrations. According to the Italian law on privacy (Art. 20-21, DL 196/2003), data were anonymized at every institution where each patient was assigned a unique identifier. This identifier did not allow to trace the patient's identity and other sensitive data.

The study population of each institution was evaluated using the TGCS (Table 1) with specific reference to the following: (1) overall CD rate, (2) relative size of each group within each institutional cohort, and (3) CD rate in each group within the obstetric population of each institution. The relative size of the groups was calculated by dividing the 
TABLE 1: 10-group classification. Groups 2 and 4 were further divided respectively in to $2 \mathrm{a}, 2 \mathrm{~b}$ and $4 \mathrm{a}, 4 \mathrm{~b}$.

\begin{tabular}{|c|c|}
\hline Group & Classification \\
\hline 1 & $\begin{array}{l}\text { Nulliparous, single cephalic, } \geq 37 \text { weeks, in spontaneous } \\
\text { labour }\end{array}$ \\
\hline $2 \mathrm{a}$ & Nulliparous, single cephalic, $\geq 37$ weeks, induced labour \\
\hline $2 b$ & $\begin{array}{l}\text { Nulliparous, single cephalic, } \geq 37 \text { weeks, CD before } \\
\text { labour }\end{array}$ \\
\hline 3 & $\begin{array}{l}\text { Multiparous (excluding previous CD), single cephalic, } \\
\geq 37 \text { weeks, in spontaneous labour }\end{array}$ \\
\hline $4 \mathrm{a}$ & $\begin{array}{l}\text { Multiparous (excluding previous CD), single cephalic, } \\
\geq 37 \text { weeks, induced labour }\end{array}$ \\
\hline $4 \mathrm{~b}$ & $\begin{array}{l}\text { Multiparous (excluding previous CD), single cephalic, } \\
\geq 37 \text { weeks, CD before labour }\end{array}$ \\
\hline 5 & Previous CD, single cephalic, $\geq 37$ weeks \\
\hline 6 & All nulliparous breeches \\
\hline 7 & All multiparous breeches (including previous CD) \\
\hline 8 & All multiple pregnancies (including previous CD) \\
\hline 9 & All transverse/oblique lies (including previous CD) \\
\hline 10 & $\begin{array}{l}\text { All preterm single cephalic, }<37 \text { weeks, including } \\
\text { previous CD }\end{array}$ \\
\hline
\end{tabular}

CD: caesarean delivery.

TABLE 2: Indications of induction of labour.

(1) Prelabour rupture of membranes

(2) Postterm (gestational age $\geq 41$ weeks)

(3) Hypertensive disorders

(4) Other maternal reasons, for example, procedure done for the benefit of the mother*

(5) Fetal reasons, for example, procedure done for the benefit of the fetus*

(6) No absolute indications or no indication reported ${ }^{*}$ Preexisting or gestational diabetes, preexisting maternal disease suggesting
the termination of pregnancy, obstetric cholestasis, alloimmunisation, severe
oligohydramnios, and intrauterine growth restriction.

number of subjects in each group by the overall obstetric population and expressed as a percentage. CD rates in each of the ten groups were calculated dividing the number of caesarean deliveries by the number of women in each of the groups.

Groups 2 (induced labour or prelabour CD in singleton, cephalic presentation, at term, nulliparous women) and 4 (induced labour or prelabour CD in singleton, cephalic presentation, at term, multiparous women) were further divided into groups $2 \mathrm{a}$ and $2 \mathrm{~b}$, and $4 \mathrm{a}$ and $4 \mathrm{~b}$, according to whether they were induced or delivered by pre-labour CD.

In each group, the indications for induction of labour and CD were reported (Tables 2 and 3). For cases in which more than one indication was present, the obstetrician was asked to report the main indication for $\mathrm{CD}$. With specific reference to dystocia, failure to progress was defined as either the absence of progressive cervical dilatation or progressive fetal descent
TABLE 3: Indications of caesarean delivery.

(1) Suspicious or pathological cardiotocography (CTG anomalies) [18]

(2) Other fetal reasons, for example, procedure done for the benefit of the fetus*

(3) Other maternal reasons, for example, procedure done for the benefit of the mother*

(4) Antepartal hemorrhage or placenta previa

(5) Preeclampsia or HELLP syndrome

(6) Breech presentation

(7) One previous caesarean delivery

(8) More than one caesarean delivery

(9) Dystocia-failed induction [19]

(10) Dystocia-failure to progress [18]

(11) No indication reported including maternal request

${ }^{*} \mathrm{HIV}$, preexisting or gestational diabetes, preexisting maternal disease suggesting the termination of pregnancy, obstetric cholestasis, alloimmunisation, severe oligohydramnios, and intrauterine growth restriction.

in the active phase of labour [18]. Failed induction was considered as the failure to achieve the active phase of labour after use of vaginal prostaglandins and/or amniotomy and infusion of oxytocin $[18,19]$. Each center was provided with a clinical practice algorithm for the assessment of these conditions; however, the management of failure to progress or failed induction was recorded by following the guidelines of the individual unit. Cardiotocographic (CTG) anomalies were categorized as suspicious and/or pathological according to specific guidelines for the interpretation of electronic fetal heart rate monitoring in labour [18].

$\mathrm{CD}$ was also classified as elective or emergency and before or during labour.

Information on maternal age, gestational age at delivery, neonatal birthweight, and perinatal mortality was also collected.

Difference in means between centers was analyzed using the ANOVA if data were normally distributed, or else with the nonparametric Kruskal-Wallis test. Post hoc analysis was carried out using Bonferroni's correction. Difference in proportion between centers were analyzed using Pearson's chi-squared test or Fisher exact test as appropriate, and the Bonferroni correction was applied in case of multiple testing. Spearman's correlation coefficient was used to study the correlations between institutional $\mathrm{CD}$ rates and relative size/CD rates in each of the ten groups and to verify whether specific indications for CD in selected groups correlated with variation of overall $\mathrm{CD}$ rates.

Categorical variables were presented as frequencies and percentages, or as percentages and 95\% confidence intervals; continuous variables were presented as mean and standard deviations.

Statistical analysis was carried out with the STATA statistical package (version 9.0) [20], and $P<0.05$ (or $P<0.05 /$ number of comparisons in case of Bonferroni correction) was considered statistically significant. 


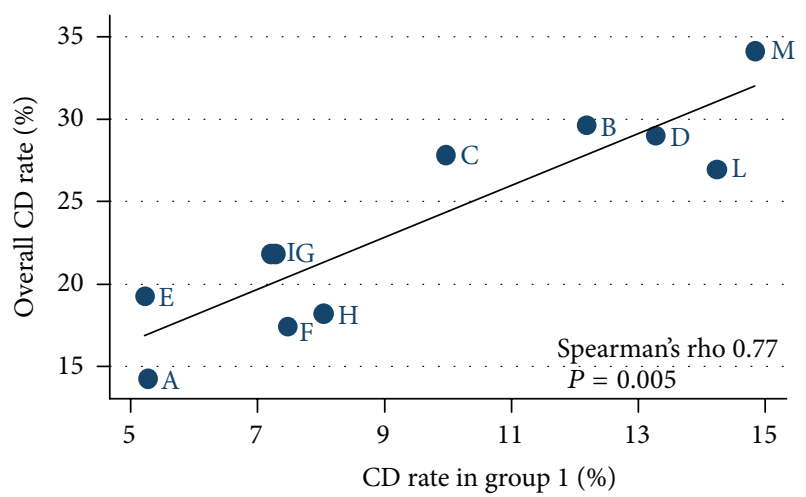

(a)

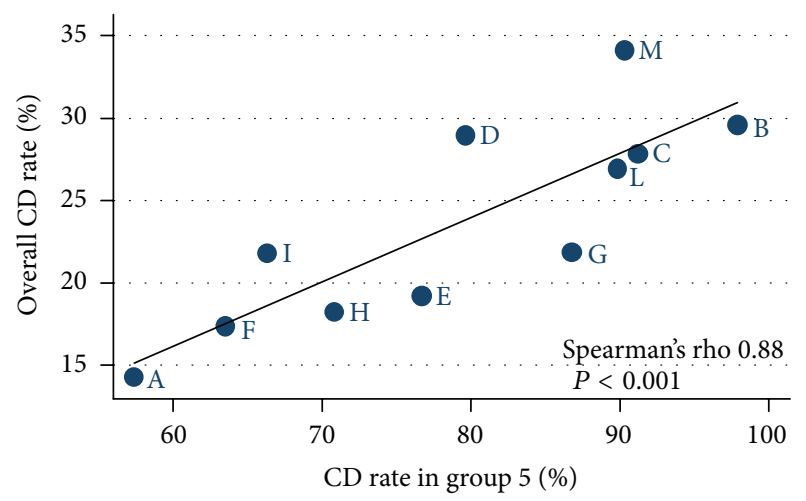

CD: caesarean delivery

(c)

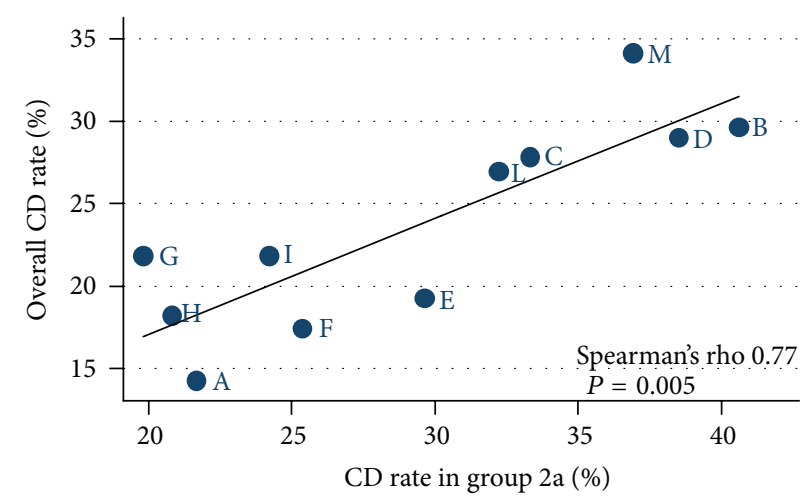

(b)

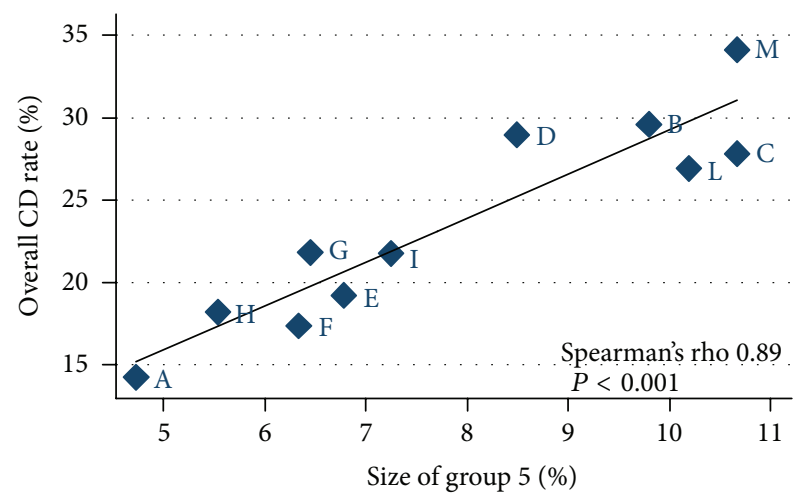

CD: caesarean delivery

FIGURE 1: Correlation between overall inter-institutional CD rates and (a) CD rates in group 1 (nulliparous women at term, cephalic presentation, spontaneous labour), (b) CD rates in group 2a (nulliparous women at term, cephalic presentation, induced labour), and (c) $\mathrm{CD}$ rates and $(\mathrm{d})$ relative size of group 5 (multiparous women at term, cephalic presentation, past CD). CD: caesarean delivery.

\section{Results}

A total of 3,791 caesarean deliveries were registered among 15,726 deliveries, giving an overall CD rate of $24.1 \%$. CD rates differed significantly among institutions (range, 14.3-34.1\%). Table 4 showed the distribution of maternal age, gestational age at birth, and neonatal birth weight among centers. Perinatal mortality rates were highest in centers serving very high-risk cases (I and M).

Distribution of the relative sizes and CD rates in each of the ten groups among centers are described in Supplemental Tables 1 and 2 (supplementary material available online at http://dx.doi.org/10.1155/2013/786563).

Pairwise comparisons among centers showed that differences in the distribution of ten groups relative sizes existed. Nulliparous women at term, cephalic presentation, spontaneous or induced labour (groups 1 and $2 \mathrm{a}$, resp.) and multiparous at term, cephalic presentation, spontaneous labour or with past CD (groups 3 and 5, resp.) were the most represented groups in all the centers (Supplemental Table 1). $\mathrm{CD}$ rates in groups $1,2 \mathrm{a}, 4 \mathrm{a}, 5,8$, and 10 differed among institutions (Supplemental Table 2).

As for the correlation between the relative size of the ten groups and the overall CD rates, only groups $2 \mathrm{~b}$ (nulliparous women, single cephalic, $\geq 37$ weeks, CD before labour; Spearman's rho $0.90, P<0.001$ ), $4 \mathrm{~b}$ (multiparous women, single cephalic, $\geq 37$ weeks, CD before labour; Spearman's rho 0.77, $P=0.006$ ), and 5 (multiparous women with past scar, single cephalic, $\geq 37$ weeks; Spearman's rho 0.89, $P<0.001$ ) were significantly correlated with the overall CD rates.

Overall CD rates correlated with $\mathrm{CD}$ rates in groups 1 (nulliparous women, single cephalic, $\geq 37$ weeks, spontaneous labour; Spearman's rho 0.77; $P=0.005$ ), 2a (nulliparous women, single cephalic, $\geq 37$ weeks, induced labour; Spearman's rho $0.77 ; P=0.005$ ), and 5 (multiparous with past scar, single cephalic, $\geq 37$ weeks; Spearman's rho $0.88 ; P<0.001-$ Figure 1).

Looking at the indications for $\mathrm{CD}$ and to their association with overall institutional $\mathrm{CD}$ rates, we decided to focus our attention on nulliparous women, single cephalic, $\geq 37$ weeks, spontaneous or induced labour (groups 1-2a) and multiparous women with past scar, single cephalic, $\geq 37$ weeks (group 5). Nulliparous and multiparous women at term, cephalic presentation, CD before labour (groups $2 \mathrm{~b}$ and $4 \mathrm{~b}$, resp.) were excluded from further analysis, firstly because the sizes of these groups were not clinically relevant (supplemental Table 1, fourth column) and secondly because, in most cases, the indications for CD were unlikely to be susceptible 


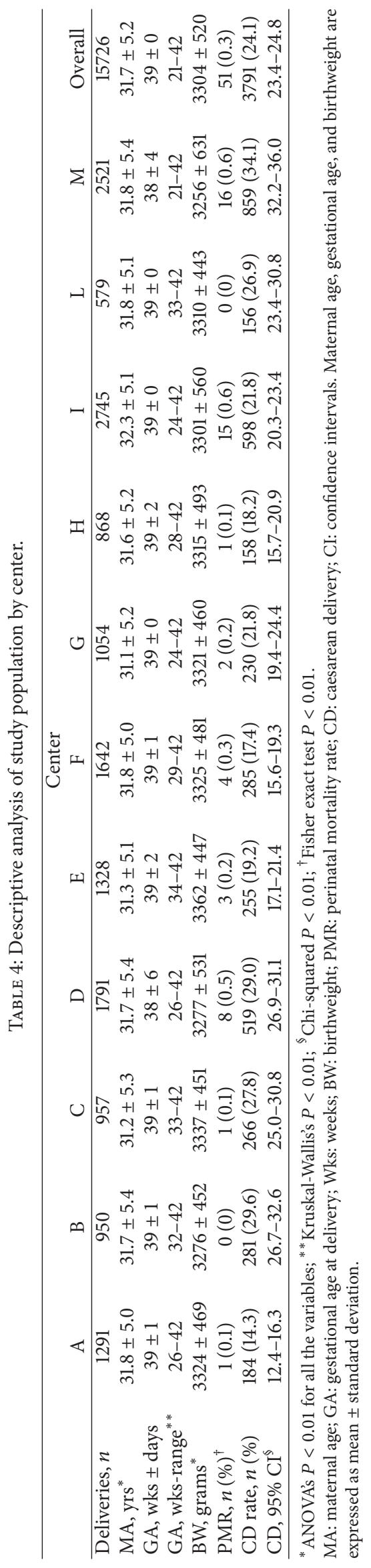




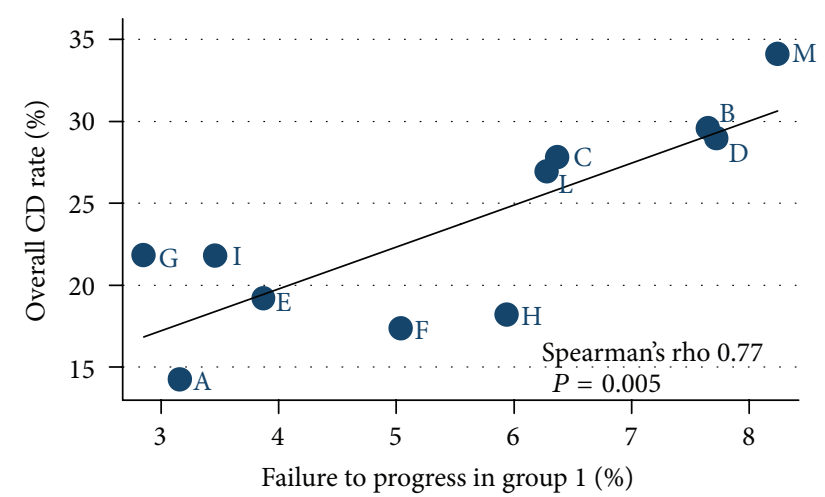

(a)

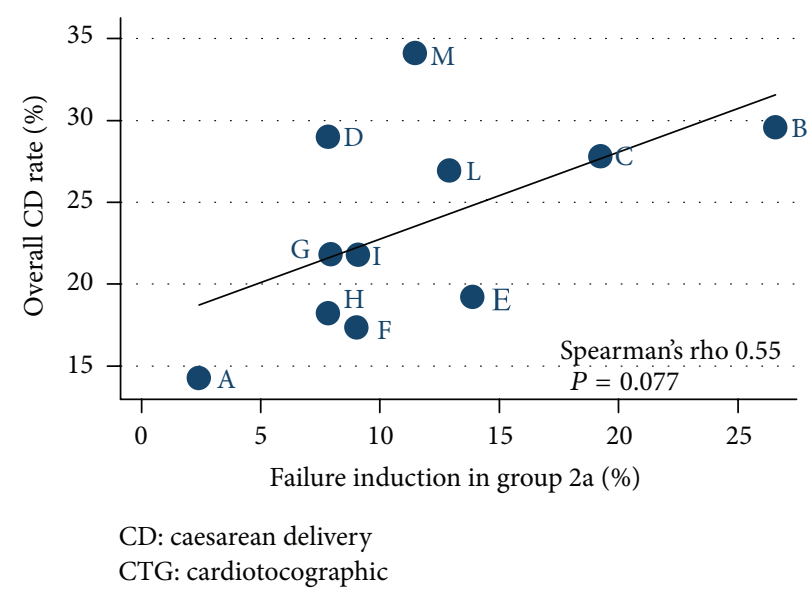

(c)

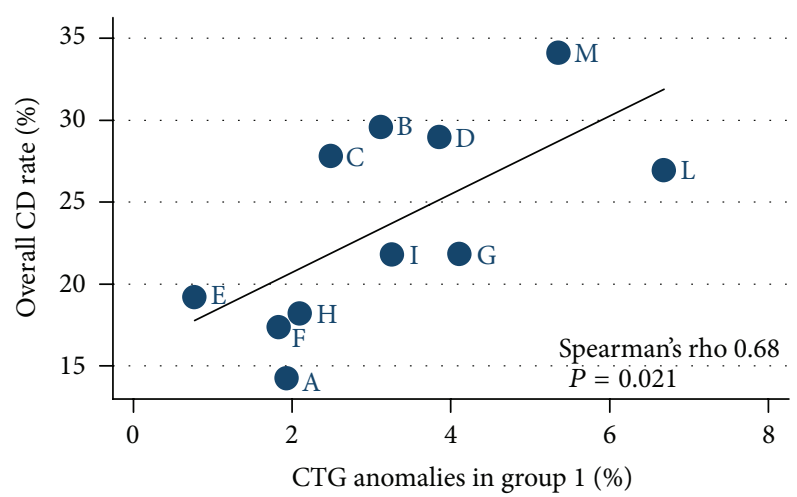

(b)

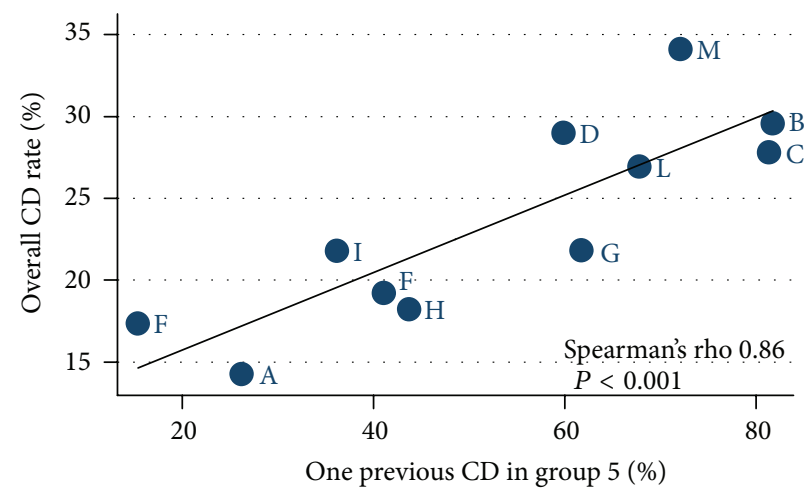

CD: caesarean delivery

CTG: cardiotocographic

(d)

FIGURE 2: Correlation between indications in selected groups and overall inter-institutional CD rates. (a) Failure to progress and (b) CTG anomalies in group 1 (nulliparous women at term, cephalic presentation, spontaneous labour); (c) failed induction in group 2a (nulliparous women at term, cephalic presentation, induced labour); (d) one previous CD in group 5 (multiparous women at term, cephalic presentation, past caesarean delivery). CD: caesarean delivery; CTG: cardiotocographic.

to modification of management (i.e., elective or emergency prelabour $\mathrm{CD}$ for absolute fetal or maternal indications).

Looking at the indications in group 1 (spontaneous labouring nulliparous women with a single cephalic pregnancy, at term), "failure to progress" and "CTG anomalies" were both significantly correlated with overall variation of CD rates (Spearman's rho 0.77; $P=0.005$ and Spearman's rho $0.68 ; P=0.021$, respectively-Figures $2(a)$ and $2(b)$ ).

The analysis of indications for CD in nulliparous women at term, in induced labour, showed that no specific indication correlated significantly with overall CD rates. Only "failed induction" demonstrated a correlation with overall CD rates, but it was not statistically significant probably due to the limited sample size of the group (Spearman's rho 0.55; $P=$ 0.077-Figure 2(c)). Of interest was the observation that the rate of induction for "no absolute indications" in group 2a was $7.8 \%(112 / 1421)$. The CD rate in this cohort was $29.4 .7 \%$ $(33 / 112)$ and "failed induction" was the main indication for CD (19/33: 57.5\%).

In the group of multiparous women, cephalic presentation at term, with at least one previous scar (group 5), there was a highly significant correlation found with the indication "one past CD" (correlation with overall CD rates: Spearman's rho 0.86; $P<0.001-$ Figure $2(\mathrm{~d})$ ). Moreover, interinstitutional variation of overall CD rates was significantly correlated with the proportion of CDs performed electively in group 5 for this indication alone (Spearman's rho 0.86; $P<0.001)$.

\section{Comment}

Our prospective evaluation of more than 15 thousand deliveries in a region with overall low $\mathrm{CD}$ rates offers new insight into the application of the TGCS. By assessing the mutually exclusive obstetric populations and providing an accurate registration of the main indications for $\mathrm{CD}$, we were able to identify which groups contributed significantly to variation of overall $\mathrm{CD}$ rates and why overall $\mathrm{CD}$ rates differed among institutions.

As suggested by the TGCS, we assessed firstly whether overall institutional $\mathrm{CD}$ rates were correlated with relative sizes or $\mathrm{CD}$ rates in specific groups. Overall CD rates correlated with $\mathrm{CD}$ rates in group 1 (nulliparous women, at term, single cephalic, spontaneous labour), in group $2 \mathrm{a}$ (nulliparous 
women, at term, single cephalic, induced labour), and with relative size and CD rates in group 5 (multiparous women, at term, cephalic presentation, with previous scar). These results strengthen the evidence that overall inter-institutional differences in $\mathrm{CD}$ rates depended on $\mathrm{CD}$ rates variations in these groups and correlated significantly with the size of multiparous women with past $\mathrm{CD}$ (group 5), a group at high risk for repeat CDs. Our observation confirmed that in order to reduce the overall $\mathrm{CD}$ rate, limiting $\mathrm{CD}$ rate in nulliparous women with a single cephalic pregnancy at term is the key to lowering the trend of overall increased abdominal deliveries. The decrease of $\mathrm{CD}$ rates in this group will consequently reduce the number of multiparous women with a previous $\mathrm{CD}$ (group 5) and hence the repeat CDs. These findings are in agreement with the results and conclusions of other studies. Brennan et al. and Delbaere et al. observed similar results, but they did not provide information about the causes of $\mathrm{CD}$ in these groups $[15,17]$. Zhang et al. described the contemporary $\mathrm{CD}$ practice in the United States and assessed the indications of CD according to the TGCS, but their experience was based on an observational study, not taking into account the interinstitutional variation of $\mathrm{CD}$ rates [12].

After having identified the groups that contributed to the overall variation of inter-institutional CD rates, we focused our attention on indications leading to $\mathrm{CD}$ in these cohorts. The aim of this evaluation was to understand whether specific indications leading to $\mathrm{CD}$ in selected groups correlated with inter-institutional variation of $\mathrm{CD}$ rates. We realized the requirement for clear, unambiguous, and precise definitions for common obstetrical diagnoses and procedures. Standardization of these definitions was an essential step to prospectively collect reliable data and to allow a consistent comparison among institutions. This was necessary to overcome the potential bias generated by differences in definitions or coding and to improve inter-institutional reproducibility of information about the obstetric conditions leading to $\mathrm{CD}$ $[21,22]$.

In the group of nulliparous women, at term, single cephalic, spontaneous labour (group 1), the indications "CTG anomalies" and "dystocia-failure to progress" contributed significantly to the overall variation of institutional CD rates. This evidence might support the hypothesis that both the management of suspicious or pathological fetal heart rate tracings and of abnormal labour differed among centers. Barber et al. found similar results. They observed that among the primary caesarean deliveries, more subjective indications ("nonreassuring fetal status" and "arrest of dilation") contributed significantly more than other more objective indications (malpresentation, maternal-fetal, and obstetric conditions) [23].

Another condition contributing to the inter-institutional variation of $\mathrm{CD}$ rates was the elective indication "one past $C D$ " in the group of multiparous, at term with previous CD. A policy of elective $\mathrm{CD}$ in women with previous $\mathrm{CD}$ was significantly associated with the increase of overall $\mathrm{CD}$ rate. Clearly, the mode of delivery of women with past CD was planned differently among institutions. Some centers, with low elective $C D$ rates for this indication, offered trial of labour, while others opted for elective $\mathrm{CD}$, probably because they considered a failed trial of labour after previous $\mathrm{CD}$ was associated with more complications than elective repeat $C D$ [24]. A recent study conducted in three Italian hospitals and dealing with the practitioners' attitudes toward the caesarean section showed that obstetricians would offer differently an elective $\mathrm{CD}$ to women with an uncomplicated single pregnancy in cephalic presentation, who had a previous CD, according to the indication of the primary $\mathrm{CD}$ [25].

It is well known that despite the presence of specific guidelines for managing anomalies of fetal heart patterns, abnormal labour, and women with a previous $\mathrm{CD}$, interinstitutional variations in clinical evaluation and management of these conditions will exist $[18,19,24,26,27]$. These variations might be care giver dependent (i.e., dystocia: different thresholds to diagnose the arrest of dilation or fetal descent) or associated with other factors difficult to evaluate, such as hospital practices or organizational settings. It has been suggested that smaller institutions often lack resources required to respond to medical emergencies in the same manner as a tertiary care facility and would thus be more likely to recommend a CD with a lower medical threshold than a larger institution [28]. In our experience, no evidence supports this hypothesis. Different CD rates for specific indications in groups $1,2 \mathrm{a}$, and 5 were observed among centers with less than 1,000 deliveries per year as well as between institutions with more than 1,000 cases per year or NICU availability (centers I versus M). Unfortunately, neither data on application of guidelines for the management of dystocia and abnormal CTG in labour nor information on the decision making process leading to elective $\mathrm{CD}$ or trial of labour in multiparous women with scar were reported. However, the aim of our study was not to assess whether clinical management is appropriate or not, but to provide institutions with a tool to critically assess their obstetric practice in specific conditions.

As for the group of nulliparous women at term, cephalic presentation, induced labour (group 2a), our data showed that induced labour in this cohort was at least three times as likely to result in CD than spontaneous labour $(29.4 \%$ and 9.5\%, resp.). However "failed induction" did not correlate significantly with overall CD rates probably because the contribution of this indication to the overall CD rate was only $5 \%$. The evidence that the rate of $\mathrm{CD}$ for "failed induction" in this group differed among institutions might support the opinion that the decision to proceed with $\mathrm{CD}$ for this indication might be not based on uniform criteria and that clinical impatience may play a role in the decision making regarding the mode of delivery. Details on management of induction of labour were not available, but this finding might be useful to audit in each center marginal indications of induction, implementing an effective management to reduce unnecessary interventions $[11,12,14]$.

The main limitation of our study was considering crude $\mathrm{CD}$ rates in each group without taking into account a number of variables that have been associated with high $\mathrm{CD}$ rates such as obesity, advanced maternal age, or clinical conditions defining the pregnancy as at risk [28-30]. However, the objective of our study was not to evaluate the adjusted $\mathrm{CD}$ rates of each institution, rather to provide a simple and immediate tool to assess which groups and indications contributed to the 
institutional CD rates [31]. Moreover, we demonstrated that the TGCS risk adjustment either with or without the inclusion of maternal characteristics and obstetrical risk factors, as predictors, might be considered as a reliable method to properly assess inter-institutional variation of CD rates [32].

Our results confirm that the TGCS represents a simple method that allows comparison of CD rates among institutions. The analysis of prospectively collected data, using standardized definitions of indications leading to CD and induction of labour in identified obstetric cohorts might be helpful to monitor and provide feedback to clinicians, identifying those procedures occurring without accepted medical indications $[27,31]$.

Our conclusions are in agreement with the remarks recently made by Robson et al. in their editorial and with the recommendations of the Society for Maternal Fetal Medicine and the American College of Obstetricians and Gynecologists. In this regard, every effort should be made to prevent the first CD in the nulliparous population by focusing the attention on caesarean deliveries occurring after labour inductions, those labeled as for "nonreassuring fetal status," and those occurring for "labour arrest" or "failed induction" without meeting accepted criteria [31,33]. This will translate in the reduction of primary $C D$ rates with subsequent decrease of women with previous $\mathrm{CD}$, at high risk of recurrence of $\mathrm{CD}$ and severe obstetric complication. In conclusion, our results support the concept that it is not relevant to argue about the rate of caesarean deliveries per se, but rather discuss how to reduce them by looking at the mode of delivery in a prospective process of labour ward audit [33, 34]. In this context, the assessment of the obstetric population according to the TGCS and the analysis of the indications leading to caesarean delivery allow to identify which groups of women contribute to the inter-institutional variation of CD rates and which are the reasons of this variation [35].

\section{Conflict of Interests}

All authors declare that there is no conflicts of interests.

\section{Authors' Contribution}

Gianpaolo Maso and Salvatore Alberico conceived and designed the study. Gianpaolo Maso, Salvatore Alberico, Luca Ronfani, Monica Piccoli, Sara Parolin, Carmine Gigli, Daniele Domini, Claudio Fiscella, Sara Casarsa, Carlo Zompicchiatti, Michela De Agostini, Attilio D’Atri, Rafaela Mugittu, Santo La Valle, Cristina Di Leonardo, Valter Adamo, Mara Fracas, Giovanni Del Frate, Monica Olivuzzi, Silvio Giove, Maria Parente, Daniele Bassini, Simona Melazzini, Silvio Giove, Secondo Guaschino, Caterina Businelli, Franco G. Toffoletti, Sergio Demarini, Laura Travan, Diego Marchesoni, Alberto Rossi, Giorgio Simon, Sandro Zicari, and Giorgio Tamburlini contributed to conducting the research and collecting data. Marcella Montico and Lorenzo Monasta analysed the data. Gianpaolo Maso, Marcella Montico, and Luca Ronfani interpreted the data. Gianpaolo Maso drafted the paper in collaboration with Monica Piccoli, Marcella
Montico, Lorenzo Monasta, Luca Ronfani, Sara Parolin, and Salvatore Alberico. Gianpaolo Maso, Monica Piccoli, Salvatore Alberico, Marcella Montico, Lorenzo Monasta, Luca Ronfani, Sara Parolin, Carmine Gigli, Daniele Domini, Claudio Fiscella, Sara Casarsa, Carlo Zompicchiatti, Michela De Agostini, Attilio D’Atri, Rafaela Mugittu, Santo La Valle, Cristina Di Leonardo, Valter Adamo, Mara Fracas, Giovanni Del Frate, Monica Olivuzzi, Silvio Giove, Maria Parente, Daniele Bassini, Simona Melazzini, Silvio Giove, Secondo Guaschino, Caterina Businelli, Franco G. Toffoletti, Sergio Demarini, Laura Travan, Diego Marchesoni, Alberto Rossi, Giorgio Simon, Sandro Zicari, and Giorgio Tamburlini met the ICMJE criteria for authorship.

\section{Acknowledgments}

This study was financed by the Grant no. 86/05 of the Institute for Maternal and Child Health (IRCCS) Burlo Garofolo, Trieste, Italy. The authors are very grateful to midwives and registrars of Friuli Venezia Giulia Institutions for their contribution to data collection and to Michael S. Robson FRCS, MRCOG, FRCPI (National Maternity Hospital, DublinIreland) for his support to revise the draft.

\section{References}

[1] A. P. Betrán, M. Merialdi, J. A. Lauer et al., "Rates of caesarean section: analysis of global, regional and national estimates," Paediatric and Perinatal Epidemiology, vol. 21, no. 2, pp. 98-113, 2007.

[2] G. Jonsdottir, A. K. Smarason, R. T. Geirsson, and R. I. Bjarnadottir, "No correlation between cesarean section rates and perinatal mortality of singleton infants over 2,500 g," Acta Obstetricia et Gynecologica Scandinavica, vol. 88, no. 5, pp. 621623, 2009.

[3] National Health Institutes National Guidelines System (SNLG), Caesarean Section: An Appropriate and Informed Choice. Guideline $n$ 19, Italian Ministry of Health's General Programming Directorate Press, Rome, Italy, 2010.

[4] M. R. Torloni, A. P. Betran, J. P. Souza et al., "Classifications for cesarean section: a systematic review," PLoS One, vol. 6, no. 1, Article ID e14566, 2011.

[5] M. S. Robson, "Classification of caesarean sections," Fetal and Maternal Medicine Review, vol. 12, pp. 23-39, 2001.

[6] M. S. Robson, "Can we reduce the caesarean section rate?" Best Practice \& Research Clinical Obstetrics \& Gynaecology, vol. 15, pp. 179-194, 2001.

[7] A. Scarella, V. Chamy, M. Sepúlveda, and J. M. Belizán, "Medical audit using the Ten Group Classification System and its impact on the cesarean section rate," European Journal of Obstetrics \& Gynecology and Reproductive Biology, vol. 154, pp. 136-140, 2011.

[8] National Collaborating Centre for Women's and Children's Health (UK), Caesarean Section-National Institute for Health and Clinical Excellence Guidance, RCOG Press, London, UK, 2011.

[9] F. P. McCarthy, L. Rigg, L. Cady, and F. Cullinane, "A new way of looking at Caesarean section births," Australian and New Zealand Journal of Obstetrics and Gynaecology, vol. 47, no. 4, pp. 316-320, 2007. 
[10] S. Howell, T. Johnston, and S.-L. MacLeod, "Trends and determinants of caesarean sections births in Queensland, 19972006," Australian and New Zealand Journal of Obstetrics and Gynaecology, vol. 49, no. 6, pp. 606-611, 2009.

[11] D. J. Brennan, M. S. Robson, M. Murphy, and C. O'Herlihy, "Comparative analysis of international cesarean delivery rates using 10-group classification identifies significant variation in spontaneous labor," American Journal of Obstetrics \& Gynecology, vol. 201, no. 3, pp. 308.e1-308.e8, 2009.

[12] J. Zhang, J. Troendle, U. M. Reddy et al., "Contemporary cesarean delivery practice in the United States," American Journal of Obstetrics \& Gynecology, vol. 203, no. 4, pp. 326.el326.10, 2010.

[13] V. M. Allen, T. F. Baskett, and C. M. O'Connell, "Contribution of select maternal groups to temporal trends in rates of caesarean section," Journal of Obstetrics and Gynaecology Canada, vol. 32, no. 7, pp. 633-641, 2010.

[14] E. P. Stavrou, J. B. Ford, A. W. Shand, J. M. Morris, and C. L. Roberts, "Epidemiology and trends for Caesarean section births in New South Wales, Australia: a population-based study," BMC Pregnancy and Childbirth, vol. 11, article 8, 2011.

[15] D. J. Brennan, M. Murphy, M. S. Robson, and C. O'Herlihy, "The singleton, cephalic, nulliparous woman after 36 weeks of gestation: contribution to overall cesarean delivery rates," Obstetrics and Gynecology, vol. 117, no. 2, pp. 273-279, 2011.

[16] I. Delbaere, H. Cammu, E. Martens, I. Tency, G. Martens, and M. Temmerman, "Limiting the caesarean section rate in low risk pregnancies is key to lowering the trend of increased abdominal deliveries: an observational study," BMC Pregnancy and Childbirth, vol. 12, article 3, 2012.

[17] E. Ciriello, A. Locatelli, M. Incerti et al., "Comparative analysis of cesarean delivery rates over a 10 -year period in a single Institution using 10-class classification," Journal of MaternalFetal and Neonatal Medicine, vol. 25, no. 12, pp. 2717-2720, 2012.

[18] National Collaborating Centre for Women's and Children's Health (UK), Intrapartum Care: Care of Healthy Women and Their Babies During Childbirth-National Institute for Health and Clinical Excellence Guidance, RCOG Press, London, UK, 2007.

[19] National Collaborating Centre for Women's and Children's Health (UK), Induction of Labour-National Institute for Health and Clinical Excellence Guidance, RCOG Press, London, UK, 2008.

[20] Stata Corporation, Stata Statistical Software: Release 9, Stata Corporation, College Station, Tex, USA, 2005.

[21] E. B. Kahn, C. J. Berg, and W. M. Callaghan, "Cesarean delivery among women with low-risk pregnancies: a comparison of birth certificates and hospital discharge data," Obstetrics and Gynecology, vol. 113, no. 1, pp. 33-40, 2009.

[22] N. Chescheir and L. Meints, "Prospective study of coding practices for cesarean deliveries," Obstetrics and Gynecology, vol. 114, no. 2, pp. 217-223, 2009.

[23] E. L. Barber, L. S. Lundsberg, K. Belanger, C. M. Pettker, E. F. Funai, and J. L. Illuzzi, "Indications contributing to the increasing cesarean delivery rate," Obstetrics and Gynecology, vol. 118, no. 1, pp. 29-38, 2011.

[24] American College of Obstetricians and Gynecologists, "ACOG Practice bulletin no. 115: vaginal birth after previous cesarean delivery," Obstetrics and Gynecology, vol. 116, no. 2, pp. 450-463, 2010.
[25] F. Monari, S. Di Mario, F. Facchinetti, and V. Basevi, "Obstetricians' and midwives' attitudes toward cesarean section," Birth, vol. 35, no. 2, pp. 129-135, 2008.

[26] M. G. Lin and D. J. Rouse, "What is a failed labour induction?" Clinical Obstetrics and Gynecology, vol. 49, pp. 585-593, 2006.

[27] E. Mozurkewich, J. Chilimigras, E. Koepke, K. Keeton, and V. J. King, "Indications for induction of labour: a best-evidence review," BJOG, vol. 116, no. 5, pp. 626-636, 2009.

[28] J. L. Bailit, T. E. Love, and N. V. Dawson, "Quality of obstetric care and risk-adjusted primary cesarean delivery rates," American Journal of Obstetrics and Gynecology, vol. 194, no. 2, pp. 402407, 2006.

[29] H.-C. Lin, T.-C. Sheen, C.-H. Tang, and S. Kao, "Association between maternal age and the likelihood of a cesarean section: a population-based multivariate logistic regression analysis," Acta Obstetricia et Gynecologica Scandinavica, vol. 83, no. 12, pp. 1178-1183, 2004.

[30] C. Athukorala, A. R. Rumbold, K. J. Willson, and C. A. Crowther, "The risk of adverse pregnancy outcomes in women who are overweight or obese," BMC Pregnancy and Childbirth, vol. 10, article 56, 2010.

[31] C. Y. Spong, V. Berghella, K. D. Wenstrom, B. M. Mercer, and G. R. Saade, "Preventing the first cesarean delivery: summary of a joint Eunice Kennedy Shriver National Institute of Child Health and Human Development, Society for Maternal-Fetal Medicine, and American College of Obstetricians and Gynecologists Workshop," Obstetrics \& Gynecology, vol. 120, pp. 11811193, 2012.

[32] G. Maso, S. Alberico, L. Monasta et al., "The application of the Ten Group classification system (TGCS) in caesarean delivery case mix adjustment. A multicenter prospective study," PloS One, vol. 8, no. 6, Article ID e62364, 2013.

[33] M. Robson, L. Hartigan, and M. Murphy, "Methods of achieving and maintaining an appropriate caesarean section rate," Best Practice \& Research Clinical Obstetrics \& Gynaecology, vol. 27, no. 2, pp. 297-308, 2013.

[34] M. S. Robson, I. W. Scudamore, and S. M. Walsh, "Using the medical audit cycle to reduce cesarean section rates," American Journal of Obstetrics and Gynecology, vol. 174, no. 1, pp. 199-205, 1996.

[35] D. Farine and D. Shepherd, "Classification of caesarean sections in Canada: the modified robson criteria," Journal of Obstetrics and Gynaecology Canada, vol. 34, pp. 976-979, 2010. 


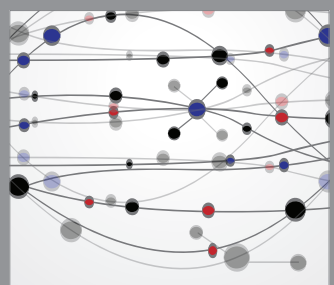

The Scientific World Journal
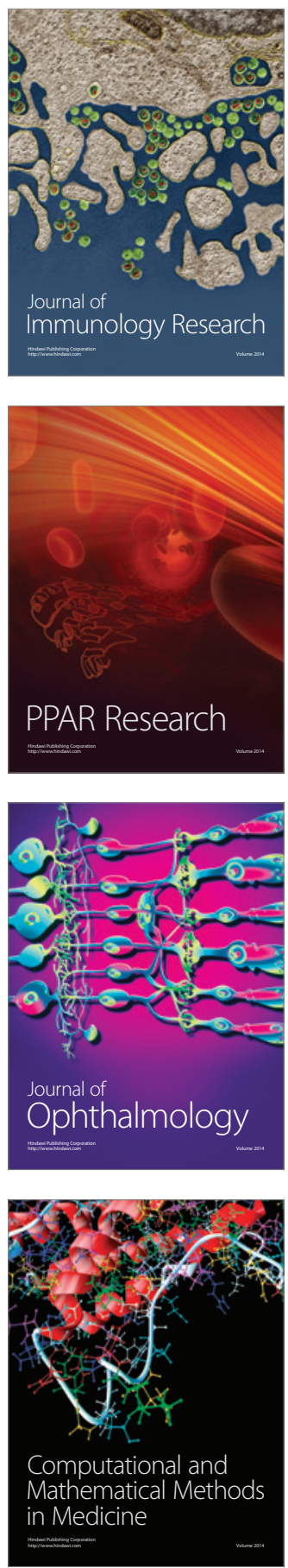

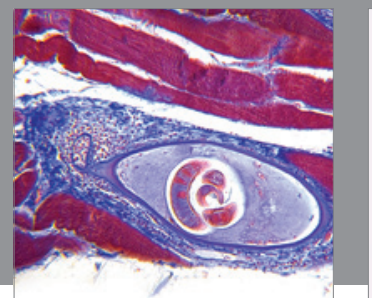

Gastroenterology

Research and Practice
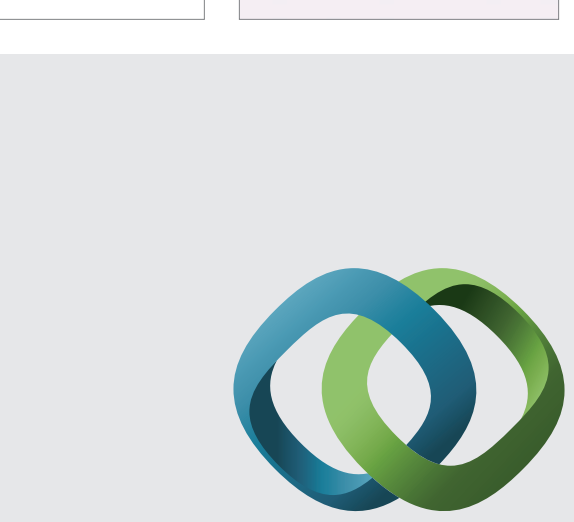

\section{Hindawi}

Submit your manuscripts at

http://www.hindawi.com
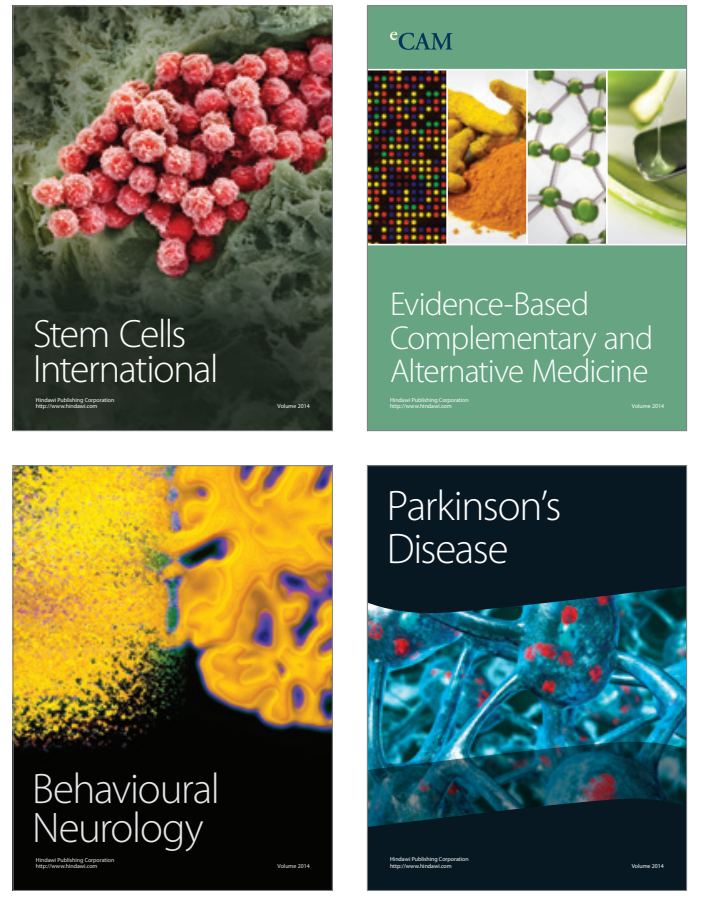
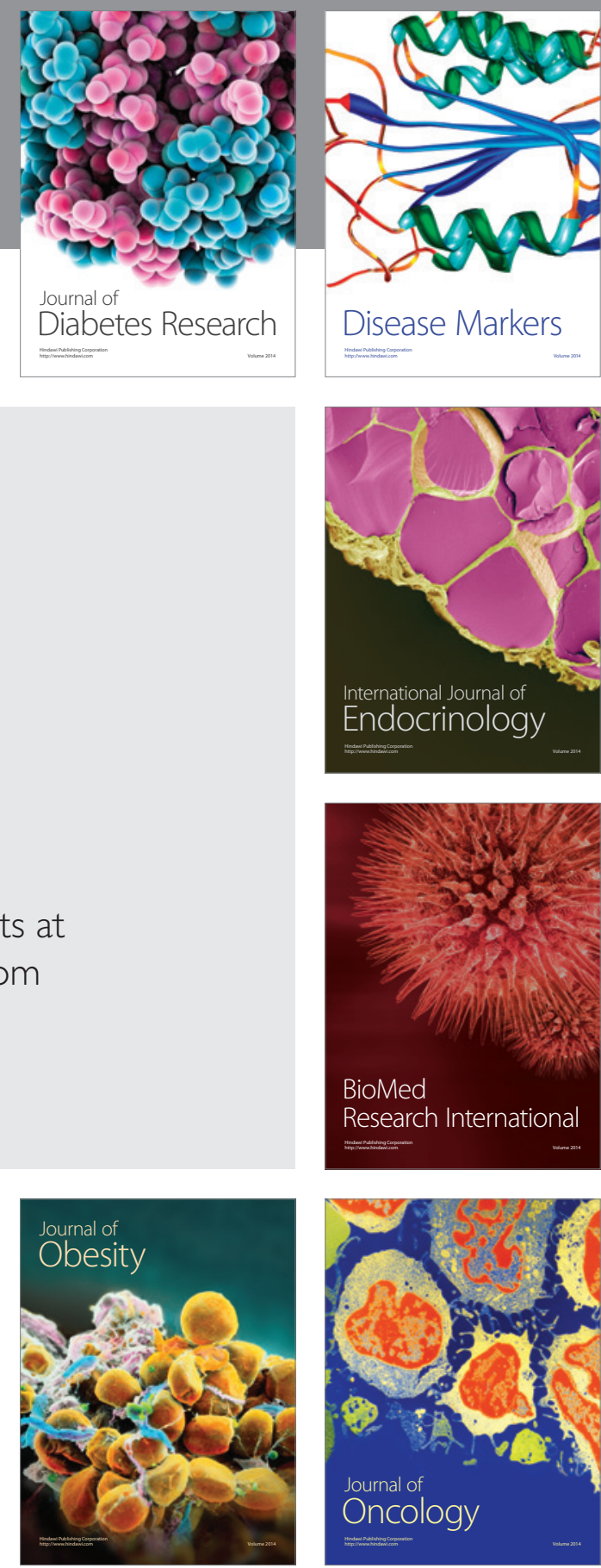

Disease Markers
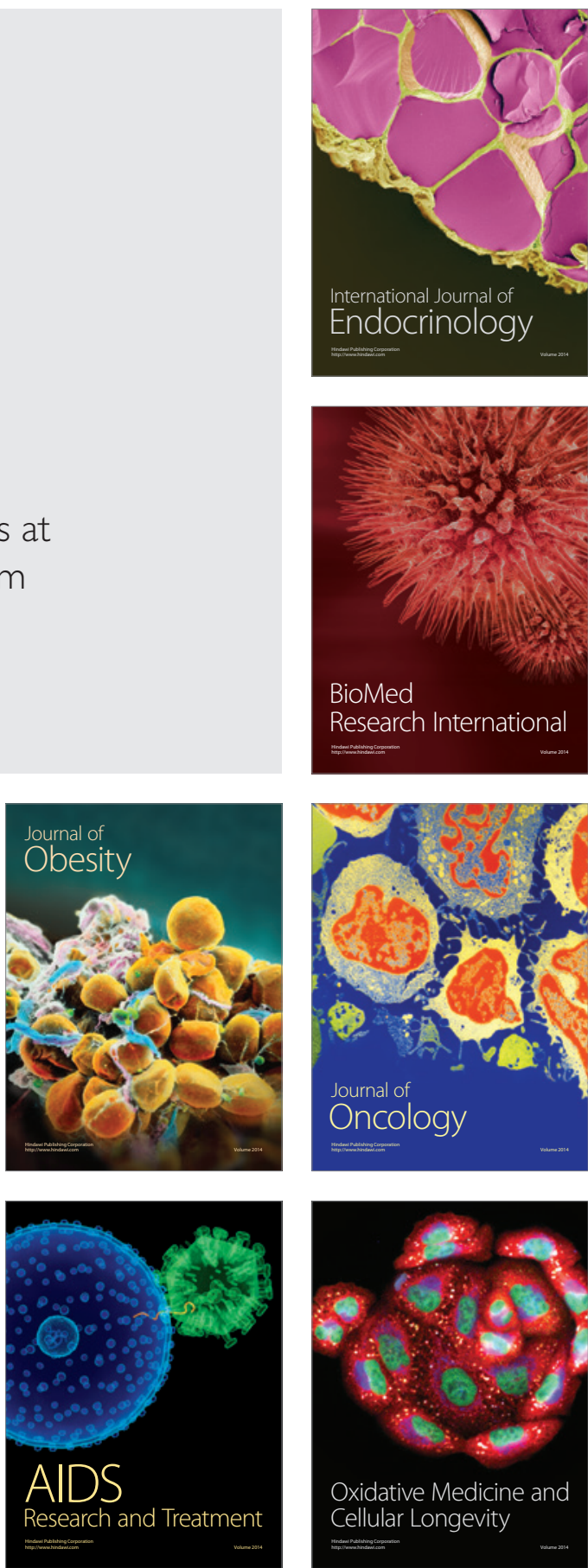